\title{
Brain-Derived Neurotrophic Factor/Tropomyosin Receptor Kinase B Signaling Controls Excitability and Long-Term Depression in Oval Nucleus of the BNST
}

\author{
Dominik Fiedler, ${ }^{1}$ Manju Sasi, ${ }^{2}{ }^{\circledR}$ Robert Blum, ${ }^{2}$ Christopher M. Klinke, ${ }^{3}{ }^{\circledR}$ Marta Andreatta, ${ }^{3,4}$ \\ Hans-Christian Pape, ${ }^{1}$ and Maren D. Lange ${ }^{1}$ \\ ${ }^{1}$ Institute of Physiology I, Westfälische Wilhelms-University Münster, 48149 Münster, Germany, ${ }^{2}$ Institute of Clinical Neurobiology, University \\ Hospital Würzburg, 97078 Würzburg, Germany, ${ }^{3}$ Department of Biological Psychology, Clinical Psychology and Psychotheraphy, Julius- \\ Maximilians-University Würzburg, 97070 Würzburg, Germany, and ${ }^{4}$ Department of Psychology, Education \& Child Studies, Erasmus University \\ Rotterdam, 3062 PA, Rotterdam, The Netherlands
}

Dysregulation of proteins involved in synaptic plasticity is associated with pathologies in the CNS, including psychiatric disorders. The bed nucleus of the stria terminalis (BNST), a brain region of the extended amygdala circuit, has been identified as the critical hub responsible for fear responses related to stress coping and pathologic systems states. Here, we report that one particular nucleus, the oval nucleus of the BNST (ovBNST), is rich in brain-derived neurotrophic factor (BDNF) and tropomyosin receptor kinase $B$ (TrkB) receptor. Whole-cell patch-clamp recordings of neurons from male mouse ovBNST in vitro showed that the BDNF/TrkB interaction causes a hyperpolarizing shift of the membrane potential from resting value, mediated by an inwardly rectifying potassium current, resulting in reduced neuronal excitability in all major types of ovBNST neurons. Furthermore, BDNF/TrkB signaling mediated long-term depression (LTD) at postsynaptic sites in ovBNST neurons. LTD of ovBNST neurons was prevented by a BDNF scavenger or in the presence of TrkB inhibitors, indicating the contribution to LTD induction. Our data identify BDNF/TrkB signaling as a critical regulator of synaptic activity in ovBNST, which acts at postsynaptic sites to dampen excitability at short and long time scales. Given the central role of ovBNST in mediating maladaptive behaviors associated with stress exposure, our findings suggest a synaptic entry point of the BDNF/TrkB system for adaptation to stressful environmental encounters.

Key words: BDNF; BNST; fear; LTD; stress; TrkB

Significance Statement

While BDNF regulates synaptic activity associated with fear learning in the amygdala, its role in the extended amygdala remains largely unknown. This is noteworthy for the bed nucleus of the stria terminals (BNST), a center for mediation of the individual fear profile, where neurons in the oval nucleus (ovBNST) can induce maladaptive behaviors in response to stress exposure. This study identifies signaling pathways of BDNF and tropomyosin receptor kinase B (TrkB) in ovBNST. BDNF/ TrkB signaling dampens neuronal excitability through an increase in membrane potassium conductance and long-term depression of synaptic activity in all types of ovBNST neurons. BDNF/TrkB thus acts at a central site for the downregulation of ovBNST activity, and thus for balancing adaptive behaviors during stressful encounters.

Received May 19, 2020; revised 0ct. 29, 2020; accepted Nov. 4, 2020

Author contributions: H.-C.P. and M.D.L. desiqned research; D.F., M.S., and R.B. performed research; D.F., M.S., M.D.L., C.M.K., M.A., and R.B. analysed data; H.-C.P., D.F., R.B., and M.D.L. wrote the paper.

Funding for this work was provided by the Deutsche Forschungsgemeinschaft (Grant SFB TRR58 B08 to M.D.L. and M.A.; and Grant SFB TRR58 A10 to R.B.), by the Interdisziplinäres Zentrum für Klinische Forschung (Project La3/013/20 to M.D.L.); and by grants from the German Excellence Initiative to the Graduate School of Life Sciences, University of Würzburg (to M.S.). We thank Melanie Becker, Petra Berenbrock, Hubert Bäumer, and Elke Naß for excellent technical assistance.

The authors declare no competing financial interests.

Correspondence should be addressed to Maren D. Lange at m.lange@uni-muenster.de.

https://doi.org/10.1523/JNEUROSCl.1104-20.2020

Copyright $\odot 2021$ the authors

\section{Introduction}

The brain-derived neurotrophic factor (BDNF) and its high affinity receptor tropomyosin receptor kinase $B(\operatorname{TrkB})$ act as mediators of neuronal and synaptic maturation, in both humans and animals (Thoenen, 1995; Park and Poo, 2013). BDNF/TrkB signaling is not restricted to developmental functions but extends to higher-order functions such as learning, memory, cognition, and the regulation of emotions (Martinowich et al., 2007; Park and Poo, 2013). Central to BDNF/TrkB signaling is an activitydependent regulation of synaptic strength, which is considered an essential property regarding learning and memory (Korte et 
al., 1995; Figurov et al., 1996; Park and Poo, 2013; Panja et al., 2014; Edelmann et al., 2015). Previous studies highlighted an involvement of BDNF in amygdala-dependent fear learning and memory. For instance, acute blockade of BDNF/TrkB signaling or mutations associated with nonfunctional TrkB receptors led to an impairment of fear learning (Rattiner et al., 2005; Ou and Gean, 2006; Musumeci et al., 2009), and fear learning-related synaptic plasticity in the lateral amygdala (LA) depends on intact BDNF/TrkB signaling (Li et al., 2011; Daftary et al., 2012). Furthermore, acute pharmacological interference with BDNF/ TrkB signaling or heterozygous genetic BDNF deletion in mice resulted in input-specific deficits of long-term potentiation (LTP) at glutamatergic synapses in LA neurons paralleling deficits in acquisition and consolidation of fear memory (Meis et al., 2012, 2018).

Brain circuits in the amygdala underlying behavioral fear have been studied in detail over the last decades (Pape and Pare, 2010; Tovote et al., 2016). More recent evidence highlights the contribution of the extended amygdala, an array of connected brain nuclei containing the bed nucleus of the stria terminalis (BNST), to a multifaceted fear response critically relating to both stress coping and pathologic systems states (Lebow and Chen, 2016; Vranjkovic et al., 2017). Exposure to various stressors is thought to link to alterations in synaptic plasticity within the BNST (Harris and Winder, 2018). However, the heterogeneous organization of BNST and transmitter systems present within its nuclei often hamper firm conclusions regarding synaptic circuits and related fear profiles (Miles and Maren, 2019). It is noteworthy here that optogenetic inhibition of the oval BNST (ovBNST), a circumscribed region in the anterodorsal BNST, dampened anxiety-like behavior and decreased respiratory rate, indicating a stress- or anxiety-provoking role of ovBNST neurons (Kim et al., 2013). In keeping with this, most neurons in ovBNST express corticotropin-releasing factor (CRF; Dabrowska et al., 2013), and chronic variable mild stress induces maladaptive behaviors through activation of CRF signaling in ovBNST neurons in mice (Hu et al., 2020). With regard to the BNST/TrkB system, chronic stress has been reported to increase transcript expression for BDNF in rats (Hammack et al., 2009), whereas defeat stress increased BDNF protein but not mRNA in BNST in the same species (Greenberg et al., 2014). Of note, both studies found changes in BDNF to be limited to anterior subregions of BNST, likely including ovBNST. Therefore, the present study was designed to assess the expression pattern of BDNF/TrkB protein in BNST in better detail with a focus on anterior subregions, and to identify synaptic mechanisms of BDNF/TrkB signaling using electrophysiological techniques combined with pharmacological techniques in BNST of mice in vitro. Results show that both BDNF and TrkB are highly abundant in ovBNST, and that BDNF/TrkB signaling dampens activity in ovBNST neurons through short-term and long-term synaptic mechanisms, thereby suggesting a synaptic entry point to BDNFmediated control of maladaptive behaviors associated with stress exposure.

\section{Materials and Methods}

Experimental design

Animals. Eight- to 12-week-old group-housed male C57BL/6J mice (Charles River Laboratories) were used for immunohistochemical experiments and whole-cell patch-clamp recordings in ovBNST neurons. Animals were kept under a $12 \mathrm{~h}$ light/dark cycle, with food and water provided ad libitum. All experiments were conducted in accordance with the European Committees Council Directive and were approved by the local authorities (Landesamt für Natur, Umwelt und Verbraucherschutz Nordrhein-Westfalen).

Chemicals and solutions. All drugs were purchased from Abcam, except for BDNF (Sigma-Aldrich) and TrkB FC (R\&D Systems). Physiologic saline for slice preparation contained the following (in $\mathrm{mM}$ ): $\mathrm{KCl} 2.5, \mathrm{NaH}_{2} \mathrm{PO}_{4} 1.25, \mathrm{MgSO}_{4} 10, \mathrm{CaCl} 20.5$, piperazine-N,N0-bis(ethanesulfonic acid) 20, glucose 10, and sucrose 200; at $\mathrm{pH} 7.35$ with $\mathrm{NaOH}$. Gabazine $(25 \mu \mathrm{M})$, CGP55845 $(10 \mu \mathrm{M})$, aminophosphonopentanoic acid $(50 \mu \mathrm{m})$, and 6,7-dinitroquinoxaline-2,3-dione $(10 \mu \mathrm{m})$ were added to the bath solution as required to block GABAergic or glutamatergic postsynaptic currents. Tetrodotoxin (TTX; $0.5 \mu \mathrm{M}$ ) was added to decrease synaptic network activity as explicitly mentioned. Respective concentrations for substances applied with the bath solution were as follows: BDNF, $1 \mathrm{~nm}$; ANA-12, $10 \mu \mathrm{M}$; K252a, $100 \mathrm{~nm}$; and TrkB FC, $100 \mathrm{ng} / \mathrm{ml}$. The extracellular solution contained artificial CSF (ACSF; in mi): $\mathrm{NaCl} 120, \mathrm{KCl} 2.5, \mathrm{NaH}_{2} \mathrm{PO}_{4} 1.25, \mathrm{MgSO}_{4} 2, \mathrm{NaHCO} 322, \mathrm{CaCl} 2$ 2 , and glucose 20 , and $\mathrm{pH}$ was maintained at 7.35 by constant gassing with carbogen $\left(95 \% \mathrm{O}_{2}, 5 \% \mathrm{CO}_{2}\right) . \mathrm{K}^{+}$-based internal solution contained the following (in mM): K-gluconate 88, K3-citrate 20, $\mathrm{NaCl} 10$, HEPES 10, BAPTA 3, phosphocreatine $15, \mathrm{CaCl} 20.5, \mathrm{MgCl} 21, \mathrm{MgATP} 3$, and NaGTP 0.5, with pH adjusted to 7.25. Voltage-clamp ramps and experiments on synaptic plasticity were performed with a $\mathrm{K}^{+}$-based internal solution containing the following (in mM): K-gluconate 120, KCL 20, HEPES 10, phosphocreatine $10, \operatorname{MgATP} 4$, and NaGTP 0.3 , with $\mathrm{pH}$ adjusted to 7.25 . BAPTA concentration was set to 10 or $30 \mu \mathrm{M}$, as indicated.

Slice preparation and electrophysiological recordings. Mice were anesthetized with isoflurane (1-chloro-2,2,2-trifluoroethyl-difluoromethylether; $2.5 \%$ in $\mathrm{O}_{2}$; Abbott) and decapitated. Coronal brain slices containing the BNST were prepared, and whole-cell patch-clamp recordings were obtained from neurons of the ovBNST, as described previously (Lange et al., 2014). Briefly, brains were removed quickly and transferred into ice-cold oxygenated physiological saline. Coronal slices $(250 \mu \mathrm{m}$ thick) containing the BNST were prepared on a vibratome (model VT1200S, Leica), and incubated in a preheated $\left(\sim 32^{\circ} \mathrm{C}\right)$, gas-flushed $\left(95 \% \mathrm{O}_{2}\right.$ and $\left.5 \% \mathrm{CO}_{2}\right)$ incubation chamber filled with ACSF.

Slices were allowed to equilibrate at room temperature (RT) for at least $1 \mathrm{~h}$ before proceeding with electrophysiological recordings. For scavenging of BDNF by TrkB FC, slices were preincubated with $5 \mu \mathrm{g} / \mathrm{ml}$ TrkB FC in an interface chamber for $2 \mathrm{~h}$. For blocking TrkB receptor activation by endogenous BDNF, slices were preincubated with $100 \mathrm{nM}$ K252a, a Trk kinase inhibitor, or $10 \mu \mathrm{M}$ ANA-12, a TrkB inhibitor, for $>30 \mathrm{~min}$, respectively. Single slices were placed in a submersion chamber at a perfusion rate of $\sim 2 \mathrm{ml} / \mathrm{min}$ (ACSF, at RT).

Electrophysiological recordings were performed with $\mathrm{K}^{+}$-based internal solutions (see "chemicals and solutions") and compensation of series resistance $\left(R_{\mathrm{s}}\right)$ by $25 \%$ was routinely used. To analyze the effect of BDNF, ovBNST neurons were recorded either in current-clamp mode at a membrane potential (MP) of approximately $-60 \mathrm{mV}$ or in voltageclamp mode at $-60 \mathrm{mV}$. BDNF was applied with the bathing solution at a perfusion speed of $\sim 4 \mathrm{ml} / \mathrm{min}$. $R_{\mathrm{s}}$ was controlled during all experiments, and cells with changes in $R_{\mathrm{s}}$ of $>30 \%$ during experiments were discarded. For experiments on intrinsic membrane properties and on spontaneous excitatory postsynaptic currents (sEPSCs) and evoked EPSCs (eEPSCs), stable recordings were obtained from an individual neuron for $10 \mathrm{~min}$ (baseline), followed by bath application of the respective substance until a near-maximal effect was obtained and washout. For experiments on intrinsic membrane properties, recordings were obtained in the presence of $\mathrm{GABA}_{\mathrm{A}}$ (gabazine; $25 \mu \mathrm{M}$ ) and $\mathrm{GABA}_{\mathrm{B}}(\mathrm{CGP} 55845 ; 10 \mu \mathrm{M})$ receptor antagonists. To investigate excitability and electrogenic properties, square-wave current pulses from -60 to $+80 \mathrm{pA}$ (pulse size varied in $10 \mathrm{pA}$ steps) were injected at a duration of $1000 \mathrm{~ms}$ in current-clamp mode at approximately $-60 \mathrm{mV}$ under baseline conditions and after $10 \mathrm{~min}$ of BDNF bath application. MP was determined as zero current potential under voltage-clamp conditions, during baseline and after $10 \mathrm{~min}$ of BDNF application. Neurons with a resting membrane potential more positive than $-50 \mathrm{mV}$ were discarded. Resting input resistance $\left(R_{\text {in }}\right)$ was calculated from the voltage deflection at 
the steady state of a $-60 \mathrm{pA}$ hyperpolarizing current. During maximal drug effect, the membrane potential was manually set to baseline values by adjusting a DC offset to exclude changes of the input resistance induced by voltage-dependent conductance. The time constant $(\tau)$ was calculated from an exponential curve fitting to the hyperpolarizing voltage deflection. Input capacitance $\left(\mathrm{C}_{\mathrm{in}}\right)$ was calculated from $\tau$ divided by $R_{\mathrm{in}} . I_{\mathrm{h}}$, indicated by depolarizing sag, was assessed during hyperpolarizing membrane responses calculated from $-60 \mathrm{mV}$ as the difference between the steadystate membrane potential at the end of a $1000 \mathrm{~ms}$ hyperpolarizing step $(-60 \mathrm{pA})$ and the most negative membrane potential at the beginning of the step. Spike threshold was assessed using the first action potential (AP) evoked by the injection of $+60 \mathrm{pA}$ current steps at $-60 \mathrm{mV}$. Spike amplitude was calculated as the difference between spike threshold and the peak of the AP. The spike half-width was measured as the width of the AP at $50 \%$ spike amplitude. The classification of cells into three previously described cell types was done by visual inspection of current-clamp traces from injection square-wave current pulses (from -60 to $+80 \mathrm{pA}$; Hammack et al., 2007; Walter et al., 2018). Briefly, the presence of an $I_{\mathrm{h}}$ depolarizing sag $(>4 \mathrm{mV})$ was taken to qualify recorded cells as type I. When the presence of the $I_{\mathrm{h}}$ sag was accompanied by rebound burst-firing behavior, cells were classified as type II. Finally, the absence of $I_{\mathrm{h}}$-indicating depolarizing sag, and the simultaneous presence of fast inward rectification, qualified cells to be type III (Hammack et al., 2007; Walter et al., 2018). To identify the BDNF-induced current, a voltage-clamp ramp protocol $(-80$ to $-120 \mathrm{mV}, 5 \mathrm{~s}$ ) was applied during baseline conditions (Ramp baseline) and during near-maximal effect of BDNF (Ramp $\mathrm{BDNF}_{\mathrm{BD}}$ ) in the presence of $1 \mu \mathrm{M}$ TTX. The BDNF-induced current was calculated as Ramp BDNF $_{-}$ Ramp baseline and plotted against the membrane potential. Points of intersection with the $x$-axis (reversal potential) were calculated from single regression lines. Spontaneous EPSCs (sEPSCs) and evoked EPSCs (eEPSCs) were recorded under voltage-clamp conditions at $-60 \mathrm{mV}$. A tungsten bipolar stimulation electrode was placed in the anterior BNST, rostral to the recorded neurons (for details, see Fig. $6 a$ ), and the stimulation strength was set to evoke $50 \%$ of the maximal EPSC amplitude (stimulus duration, $500 \mu \mathrm{s}$; interstimulus interval, $20 \mathrm{~s}$ ). The latency was measured between the stimulation artifact and the onset of the postsynaptic responses. Responses with latencies $<5 \mathrm{~ms}$ were accepted for analysis. The paired-pulse ratio (PPR) was obtained by applying two consecutive stimuli at an interval of $100 \mathrm{~ms}$, and dividing the amplitude of the second response by the amplitude of the first response. Results were compared at baseline and the near-maximal response to BDNF. To control for possible rundown effects, ACSF with no added BDNF (control) was applied in a separate group of neurons. Long-term depression (LTD) was induced by a low-frequency stimulation (LFS) protocol (Puente et al., 2011) consisting of $10 \mathrm{~Hz}$ stimuli for $10 \mathrm{~min}$, and stimulation strength was set to evoke $50 \%$ of the maximal EPSC amplitude. After LFS, eEPSCs were monitored for at least $45 \mathrm{~min}$. For quantification, the amplitudes of eEPSCs were normalized to the mean amplitude of 30 evoked responses during $5 \mathrm{~min}$ of baseline stimulation. LTD was analyzed by comparing mean baseline responses with mean amplitudes of eEPSCs $40-45$ min (30 responses) after LFS, given as the percentage of the reduction of eEPSC amplitudes. Neurons with resting membrane potential positive to $-50 \mathrm{mV}$ were rejected from analysis. Data analysis was performed using Pulse software (HEKA) and Clampfit software (Molecular Devices) for offline analysis.

Immunohistochemistry. Mice were deeply anesthetized with a mixture of ketamine $(120 \mathrm{mg} / \mathrm{kg}$ body weight $)$ and xylazine $(16 \mathrm{mg} / \mathrm{kg}$ body weight). Then, mice were transcardially perfused with PBS containing $0.4 \%$ heparin $\left(4^{\circ} \mathrm{C}\right)$ followed by freshly prepared, prewarmed $\left(37^{\circ} \mathrm{C}\right) 4 \%$ PBS-buffered paraformaldehyde (PFA), pH 6.0. The brains were postfixed in $4 \%$ PFA, pH 6.0, for only $2 \mathrm{~h}$ to prevent overfixation. After postfixation, fixed brains were washed twice in $10 \mathrm{ml}$ of PBS and finally stored in PBS until sectioning. Coronal sections ( $40 \mu \mathrm{m}$ thick) were made with a vibratome (model VT1000S, Leica). For long-term storage, slices were transferred to a cryoprotectant solution ( $30 \%$ ethylene glycol, $25 \%$ glycerol, $0.4 \mathrm{M}$ phosphate buffer, $\mathrm{pH} 7.4$ ) and stored at $-20^{\circ} \mathrm{C}$. Vibratome slices stored in cryoprotectant solution were washed twice with $1 \times$ PBS for $15 \mathrm{~min}$ before labeling. For immunolabeling, antigen retrieval was performed in $10 \mathrm{~mm}$ sodium citrate, $\mathrm{pH} 8.5$, at $80^{\circ} \mathrm{C}$ for $30 \mathrm{~min}$ in $1.5 \mathrm{ml}$ tubes in a thermomixer (Eppendorf) followed by cooling down to room temperature. Free-floating coronal sections were washed twice with $1 \times$ PBS and incubated for $1 \mathrm{~h}$ in blocking solution ( $10 \%$ horse serum, $0.3 \%$ Triton X-100, and $0.1 \%$ Tween 20 in PBS, pH 7.4). Primary antibodies were diluted in the same solution and were incubated for $2 \mathrm{~d}$ at $4^{\circ} \mathrm{C}$. Washing of the slices was performed three times in PBS, $0.1 \%$ Triton X-100, and $0.1 \%$ Tween 20 for $10 \mathrm{~min}$. Secondary antibodies, diluted in blocking solution, were incubated for $1.5 \mathrm{~h}$ at room temperature. Finally, slices were washed again, and cell nuclei were labeled with DAPI $(0.4 \mu \mathrm{g} / \mathrm{ml})$. Sections were finally embedded in Aqua-PolyMount (Polysciences) and were imaged by confocal microscopy.

The following primary antibodies were used: mouse anti-BDNF (mAB9; Developmental Studies Hybridoma Bank, University of Iowa), affinity-purified anti-BDNF-9, $2.75 \mu \mathrm{g} / \mathrm{ml}$ ); chicken anti-Neurofilament $\mathrm{H}(2.5 \mu \mathrm{g} / \mathrm{ml}$; catalog \#AB5539, Millipore); guinea pig anti-NeuN (neuronal-specific nuclear protein; Fox $3 ; 0.3 \mu \mathrm{l}$ of antiserum $/ \mathrm{ml}$; catalog \#266004, Synaptic Systems); goat anti-TrkB $(0.5 \mu \mathrm{g} / \mathrm{ml}$; catalog \#AF1494, R\&D Systems). The following secondary antibodies were used: donkey anti-guinea pig Alexa Fluor 488 (catalog \#706-545-148, The Jackson Laboratory); goat anti-chicken Alexa Fluor 488 (catalog \#A11039, Thermo Fisher Scientific); donkey anti-goat Cy3 (catalog \#705-165-147, The Jackson Laboratory); and donkey anti-mouse Cy3 (catalog \#715165-151, The Jackson Laboratory).

Confocal images were acquired using an Olympus IX81 microscope equipped with an Olympus FV1000 confocal laser-scanning system and an FVD10 SPD detector. Diode lasers (405, 473, and $559 \mathrm{~nm}$ ) were used for fluorophore excitation. All images shown were acquired with Olympus objectives ( $10 \times$ UPlan SAPO, 0.4 numerical aperture; UPlan Sapo $20 \times, 0.75$ numerical aperture; UPlanFLN 40×, 1.30 numerical aperture; and UPlanFLN $60 \times, 1.35$ numerical aperture). Pinhole setting represented one Airy disk. Twelve bit $z$-stack images were processed by maximum intensity projection and were adjusted in brightness and contrast using ImageJ software. Final figure preparation was performed in Adobe Photoshop CS5.

\section{Statistical analysis}

Data are presented as the mean \pm SEM. The number of experiments is given as ( $n$ cells $/ n$ animals). Data were analyzed using repeated-measures ANOVA, one-sample $t$ test, or nonparametric Kolmogorov-Smirnov test, as applicable. Multiple post hoc comparisons were Bonferroni corrected. Statistically significant outliers were identified and excluded from analysis by using Grubb's test (significance level, $p<0.05$ ). Statistical analyses were conducted using Prism version 7.04 (GraphPad Software). Statistical significance for all experiments was set on $p<0.05$ and is indicated as follows: $* p<0.05 ; * * p<0.01 ; * * * p<0.001$.

The excitability of ovBNST neurons was analyzed by repeated-measures ANOVA using group (baseline; BDNF) as the between-subjects factor and current injected $(+80 \mathrm{pA})$ as within-subjects factor. Intrinsic membrane properties were analyzed using an unpaired $t$ test comparing the mean of the respective characteristics in a given neuron at baseline and during the near-maximal effect of BDNF. The frequency and amplitude of sEPSCs as well as the amplitude and PPR of eEPSCs were analyzed by repeated-measures ANOVA using group (controls, BDNF) as the between-subjects factor and time (baseline, washin $\mathrm{BDNF} /$ control) as the within-subject factor. Cumulative probabilities of frequencies and amplitudes of sEPSCs were analyzed by using a nonparametric Kolmogorov-Smirnov test ( $n=17,50$ events each, 850 events in total per group; baseline, BDNF). Holding current and membrane potential (see Fig. 4) were analyzed by repeated-measures ANOVA using group (controls, BDNF, K252a, ANA-12 for holding current; controls, BDNF, BAPTA for membrane potential) as the between-subjects factor and time (baseline, washin BDNF/control, washout) as the within-subject factor. Synaptic plasticity was analyzed by repeated-measures ANOVA using group (no stimulation, LTD, BDNF, BAPTA $10 \mu \mathrm{M}$, BAPTA $30 \mu \mathrm{M}, \mathrm{ANA}-12, \mathrm{~K} 252 \mathrm{a}, \operatorname{TrkB} \mathrm{FC})$ as the between-subjects factor and time (baseline, $40-45 \mathrm{~min}$ ) as the within-subject factor. 


\section{Results}

Immunohistochemical staining of BDNF and TrkB in BNST To investigate the abundance and distribution of BDNF and its high-affinity receptor TrkB within the BNST, we performed immunohistochemical staining using $40 \mu \mathrm{m}$ coronal sections (Fig. 1) prepared from a total of three mice. Slices were stained with antibodies against NeuN (Fox3), a commonly used marker to label neurons. In accordance with an earlier study (Conner et al., 1997), BDNF was found to be highly present within the BNST, specifically in the ovBNST (Fig. 1a,b). BDNF was widely distributed in the neuropil of the ovBNST and was abundantly enriched in the perinuclear region of many ovBNST cells (Fig. 1d,e, white arrows). TrkB was labeled with an antibody against the extracellular domain. This antibody detects both TrkB kinase and TrkB$\mathrm{T} 1$, a truncated, kinase-deficient TrkB isoform. TrkB was found to be widely distributed within the BNST (Fig. 1c). The labeling shows that both BDNF and TrkB are highly abundant in the ovBNST.

\section{BDNF effects on excitability and basal synaptic transmission of ovBNST neurons}

In a next experimental step, the effect of BDNF on ovBNST neurons was assessed using whole-cell patch-clamp techniques. For analyzing neuronal excitability, in vitro brain slices, including the BNST, were prepared and single neurons of the ovBNST were electrophysiologically recorded under current-clamp condition in the presence of gabazine and CGP55845. Three major types of neurons have been identified in BNST, including ovBNST. In brief, type I neurons are regular spiking, while type II neurons generate a low-threshold burst. Both types of neurons display slowly developing depolarizing sag on maintained membrane hyperpolarization. Type III neurons display fast inward rectification in the hyperpolarizing direction (Hammack et al., 2007; Walter et al., 2018). To test whether BDNF differentially affects the types of neurons in ovBNST, recorded neurons were assigned to the different cell types (types I-III) based on these electrophysiological properties. The effects of BDNF on excitability and intrinsic membrane properties of ovBNST types I-III neurons were investigated by comparing single-cell recordings under baseline conditions with recordings of the same cells after $10 \mathrm{~min}$ of BDNF (10 nM) application. Action potentials and intrinsic membrane properties were analyzed by the injection of rectangular current pulses ( $1000 \mathrm{~ms}$ duration; -60 to $+80 \mathrm{pA} ; 10 \mathrm{pA}$ increases in step size) at $-60 \mathrm{mV}$ holding potential (Fig. 2a). To monitor BDNF-induced changes, the membrane potential was manually set to baseline values by adjusting a DC offset during maximal drug effect. BDNF significantly reduced the number of evoked action potentials compared with baseline conditions in all three types of ovBNST neurons (Fig. 2b). For type I neurons $(n=11 / 9)$, repeated-measures ANOVA revealed a significant time $\times$ group interaction $\left(F_{(8,80)}=3.938, p<0.001\right)$, main effect of time $\left(F_{(8,80)}=105.300, p<0.001\right)$, and main effect of group $\left(F_{(1,10)}=16.680, p=0.002\right)$. Subsequent post hoc analysis revealed a significant decrease in the number of spikes for $+20 \mathrm{pA}$ $(p<0.001),+30 \mathrm{pA}(p<0.001),+40 \mathrm{pA}(p<0.001),+50 \mathrm{pA}$ $(p<0.001),+60 \mathrm{pA}(p<0.001)$, and $+70 \mathrm{pA}(p=0.01)$. For type II neurons $(n=9 / 6)$, repeated-measures ANOVA revealed a significant time $\times$ group interaction $\left(F_{(8,64)}=3.553, p=0.002\right)$, main effect of time $\left(F_{(8,64)}=20.160, p<0.001\right)$, and main effect of group $\left(F_{(1,8)}=6.063, p=0.04\right)$. Subsequent post hoc analysis revealed a significant decrease in number of spikes for $+50 \mathrm{pA}(p=0.002)$, $+60 \mathrm{pA}(p=0.001),+70 \mathrm{pA}(p<0.001)$, and $+80 \mathrm{pA}(p<0.001)$.
For type III neurons $(n=12 / 9)$, repeated-measures ANOVA revealed a significant time $\times$ group interaction $\left(F_{(8,88)}=7.540\right.$, $p<0.001)$, main effect of time $\left(F_{(8,88)}=76.900, p<0.001\right)$, and main effect of group $\left(F_{(1,11)}=20.440, p<0.001\right)$. Subsequent post hoc analysis revealed a significant decrease in the number of spikes for $+20 \mathrm{pA}(p<0.001),+30 \mathrm{pA}(p<0.001),+40 \mathrm{pA}(p<0.001)$, $+50 \mathrm{pA}(p<0.001),+60 \mathrm{pA}(p<0.001),+70 \mathrm{pA}(p<0.001)$, and $+80 \mathrm{pA}(p<0.006)$. Furthermore, BDNF induced a hyperpolarizing shift of the membrane resting potential in all three types of ovBNST neurons (type I, $p=0.03$; type II, $p=0.04$; type III, $p=0.001$ ), whereas other intrinsic membrane properties were not significantly affected, as revealed by Student's $t$ test analysis (Fig. 2c, table). Since BDNF application similarly affected intrinsic properties of all recorded neurons in ovBNST, with no apparent differences occurring between types of neurons, results were pooled from recorded neurons in the following. In a next experimental step, the effect of BDNF on basal glutamatergic synaptic transmission of ovBNST neurons was assessed. Basic glutamatergic synaptic properties were analyzed under voltage-clamp conditions in the presence of gabazine and CGP55845 (Fig. 3). Bath application of BDNF had no effect on both average frequency (time $\times$ group interaction: $F_{(1,27)}=$ $0.6884, p=0.41$; main effect of time: $F_{(1,27)}=2.675, p=0.11$; main effect of group: $\left.F_{(1,27)}=0.4329, p=0.52\right)$ and average amplitude (time $\times$ group: $F_{(1,27)}=0.3333, p=0.57$; main effect of time: $F_{(1,27)}=1.217, p=0.28$; main effect of group: $F_{(1,27)}=$ $0.9189, p=0.35$ ) of sEPSCs compared with controls (Fig. $3 a$ ). Cumulative probability plots of sEPSCs revealed a different distribution of frequencies but not amplitudes (KolmogorovSmirnov test; frequency, $p<0.001$; amplitude, $p=0.47$; baseline/BDNF events, $n=850$ ) during baseline and after BDNF application (Fig. 3b). For eEPSCs compared with controls, bath application of BDNF had no significant effect on both amplitude (time $\times$ group interaction: $F_{(1,11)}=1.927, p=0.19$; main effect of time: $F_{(1,11)}=0.3646, p=0.56$; main effect of group: $\left.F_{(1,11)}=0.6194, p=0.45\right)$ and PPR (time $\times$ group interaction: $F_{(1,12)}=0.03,617, p=0.85$; main effect of time: $F_{(1,12)}=0.7961$, $p=0.39$; main effect of group: $F_{(1,12)}=1.056, p=0.32$; Fig. $3 c$ ).

\section{BDNF induces an increase in membrane $\mathrm{K}^{+}$conductance in ovBNST neurons}

To identify mechanisms of BDNF in ovBNST neurons, we applied $\mathrm{BDNF}$ at $-60 \mathrm{mV}$ under voltage-clamp conditions. BDNF evoked an outward membrane current in 14 neurons recorded in BNSTov slices from 9 animals (Fig. 4a). Repeated-measures ANOVA revealed a significant time $\times$ group interaction $\left(F_{(6,80)}=\right.$ 6.936, $p<0.001)$, main effect of time $\left(F_{(2,80)}=19.59, p<0.001\right)$, and main effect of group $\left(F_{(3,40)}=3.148, p=0.04\right)$. Subsequent post hoc analysis revealed a significant increase in holding current in response to BDNF compared with baseline $(p<0.001)$ and compared with non-BDNF-treated controls $(p<0.001)$. To investigate whether this effect was mediated by TrkB receptors, we additionally added K252a, to block Trk kinase activity, or added ANA-12, a directly acting antagonist of TrkB receptors. Either condition, K252a or ANA-12 treatment, prevented the hyperpolarizing BDNF effect. No significant differences in holding current compared with baseline were observed when BDNF was applied in the presence of K252a or ANA-12 (K252a, $p=0.67$; ANA-12, $p=0.87$ ) and compared with controls (K252a, $p>0.99$; ANA-12, $p>0.99$ ). Additionally, BDNF-treated cells showed a significantly increased holding current compared with K252a- and ANA-12treated cells (K252a, $p=0.004$; ANA-12, $p<0.001$ ). After washout for $10 \mathrm{~min}$, cells still showed a significant increase in holding 

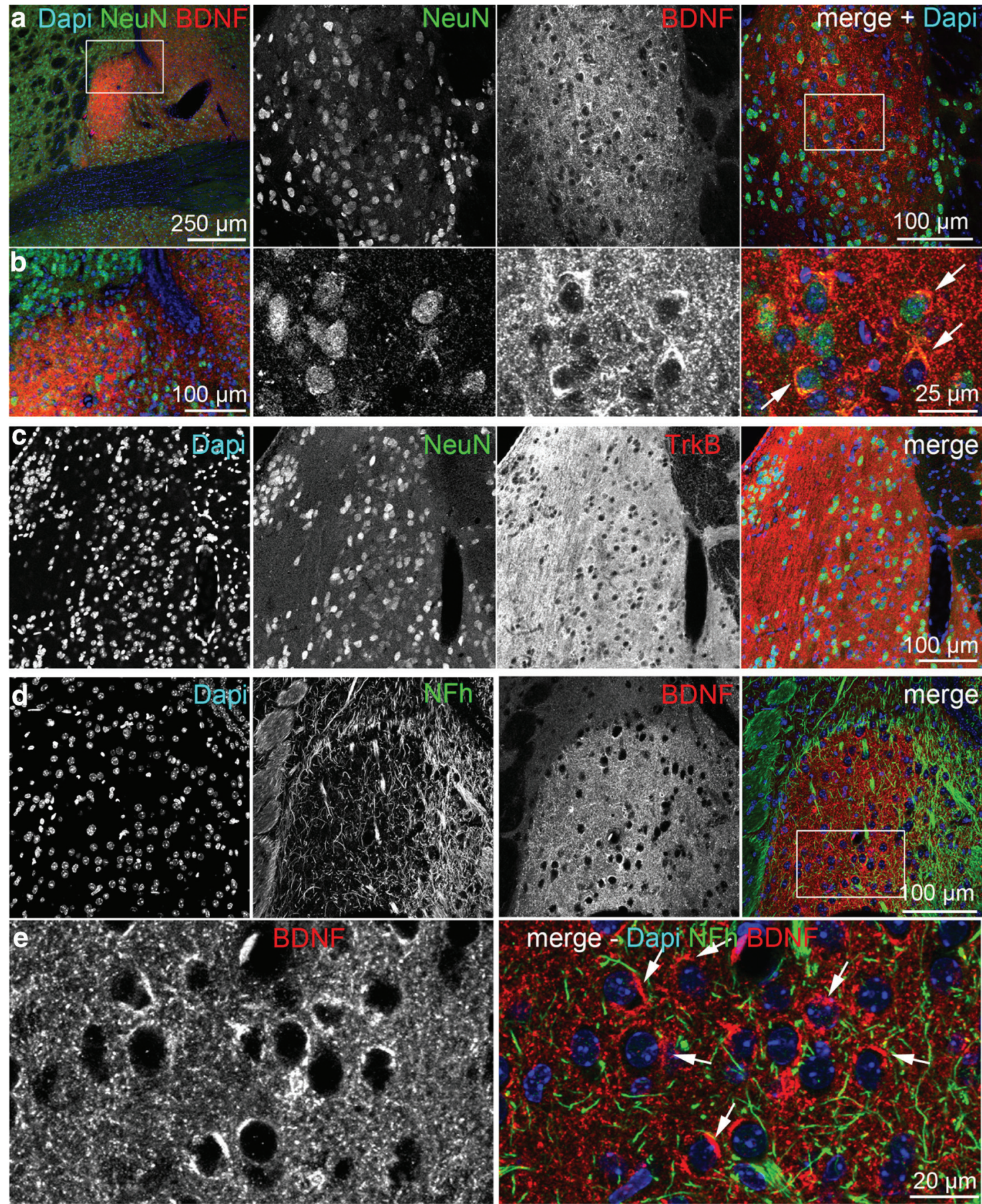

Figure 1. BDNF and its receptor TrkB are abundantly available in the ovBNST. $\boldsymbol{a}, \boldsymbol{b}$, Representative immunohistochemical staining of BDNF (red), NeuN (green), and DAPI (blue) in the ovBNST. BDNF immunoreactivity in the ovBNST was most obvious in the neuropil and in perinuclear structures of cell somata (white arrows). $c$, Representative immunohistochemical staining of TrkB (red), NeuN (green), and DAPI (blue) in the BNST. TrkB is abundantly available within the ovBNST. $\boldsymbol{d}$, $\boldsymbol{e}$, Detailed immunohistochemical staining of BDNF in the ovBNST. BDNF was labeled with anti-BDNF (mab\#9). Neurofilament heavy chain was used as a counterstain, and DAPI was used to label nuclei. Confocal images were acquired with a $40 \times$ objective, a numerical aperture of 1.3, at a resolution of $310 \mathrm{~nm} / \mathrm{pixel}$, airy disk 1. Top, Maximum intensity projection of a $z$-stack of $10 \mu \mathrm{m}$. Bottom, Magnification view, as indicated in the inset. Maximum intensity projection, $z$-stack of $4 \mu \mathrm{m}$. Arrows point to perinuclear regions in the confocal slice.

current compared with baseline $(p<0.001)$. Under current-clamp conditions with TTX $(0.05 \mu \mathrm{M})$ added to the bathing solution, BDNF caused a hyperpolarizing shift of the membrane potential (Fig. 4b). Repeated-measures ANOVA revealed a significant time $\times$ group interaction $\left(F_{(4,34)}=4.332, p=0.006\right)$, main effect of time $\left(F_{(2,34)}=4.211, p=0.02\right)$, and main effect of group $\left(F_{(2,17)}=3.969\right.$, $p=0.04)$. Subsequent post hoc analysis revealed a significant hyperpolarizing shift of the membrane potential in response to BDNF application compared with baseline $(p<0.001)$ and compared with controls $(p<0.001)$. To investigate whether this effect is mediated presynaptically or postsynaptically, the calcium chelator BAPTA $(10 \mu \mathrm{M})$ was added to the internal solution. BAPTA prevented the BDNF effect as there were no significant differences in membrane potential when BDNF was applied compared with baseline $(p>0.99)$ and compared with controls $(p>0.99)$. Additionally, BDNF-treated cells showed significant membrane hyperpolarization 
a

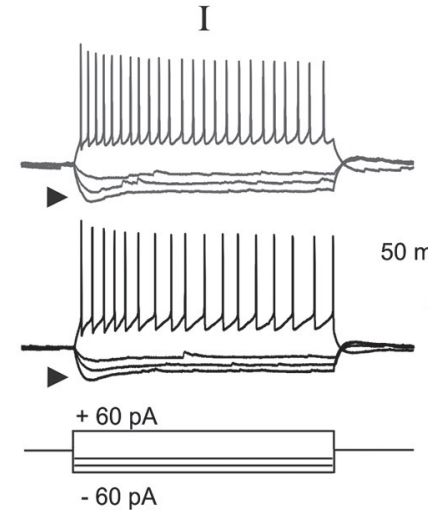

b

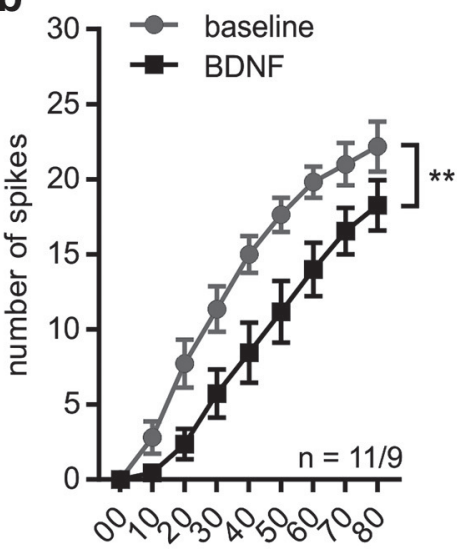

current injected $(\mathrm{pA})$
II
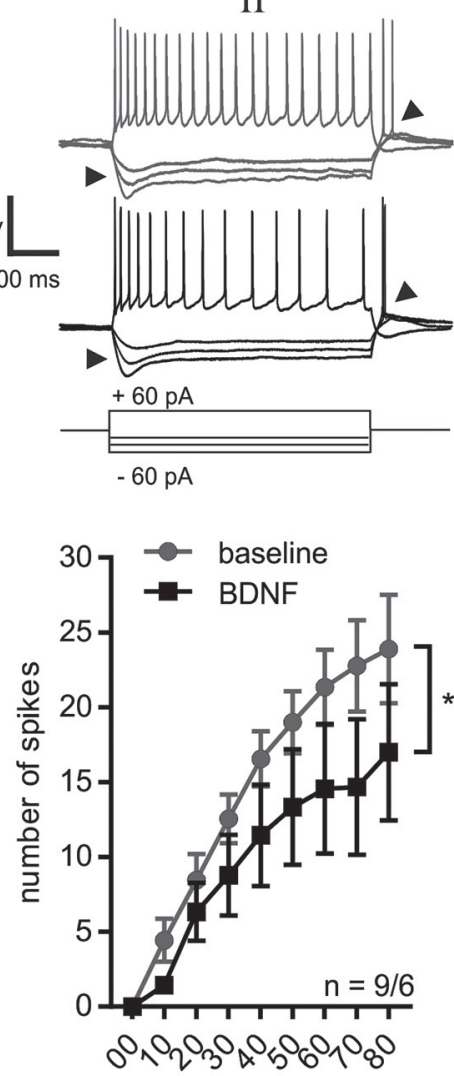

current injected $(p A)$
III
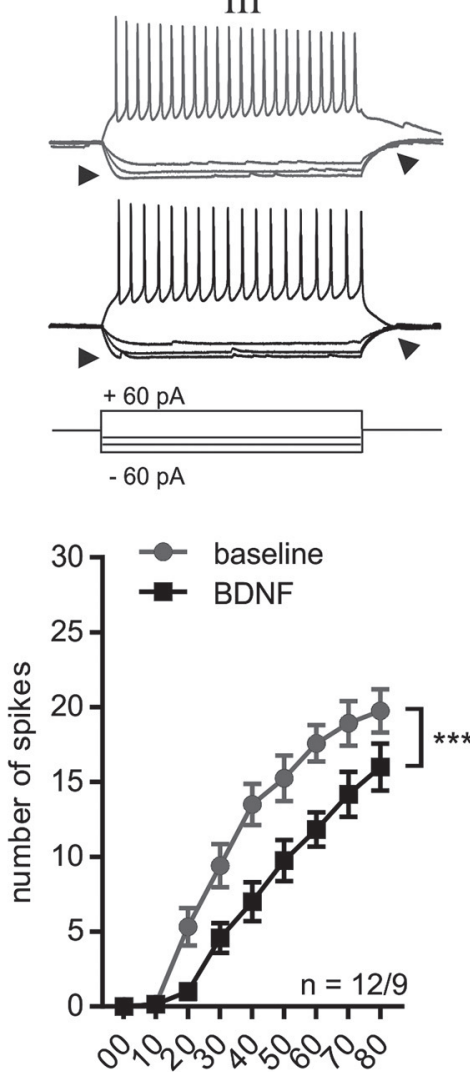

current injected $(p A)$

C

\begin{tabular}{l|cc|cc|cc} 
& \multicolumn{2}{|c}{ type I } & \multicolumn{2}{c}{ type II } & type III \\
& baseline & BDNF & baseline & BDNF & baseline & BDNF \\
\hline MP $(\mathrm{mV})$ & $-59.3 \pm 2.3$ & $-63.6 \pm 1.8^{*}$ & $-58.4 \pm 2.5$ & $-59.6 \pm 2.9^{*}$ & $-70.3 \pm 1.9$ & $-73.1 \pm 2.0^{* *}$ \\
$\mathrm{R}(\mathrm{in})(\mathrm{M \Omega})$ & $466.9 \pm 39.2$ & $463.3 \pm 42.2$ & $556.8 \pm 42.9$ & $558.9 \pm 45.5$ & $399.5 \pm 20.3$ & $390.9 \pm 24.9$ \\
$\mathrm{C}_{\mathrm{in}}(\mathrm{pF})$ & $59.8 \pm 5.3$ & $57.2 \pm 6.9$ & $45.8 \pm 5.1$ & $45.1 \pm 4.3$ & $63.6 \pm 5.8$ & $66.0 \pm 7.2$ \\
$\tau(\mathrm{ms})$ & $26.5 \pm 1.7$ & $24.7 \pm 2.0$ & $24.1 \pm 2.0$ & $23.8 \pm 1.4$ & $25.4 \pm 2.8$ & $25.0 \pm 2.6$ \\
Sag $(\mathrm{mV})$ & $6.3 \pm 0.7$ & $5.0 \pm 0.7$ & $9.6 \pm 1.3$ & $8.72 \pm 1.3$ & $2.1 \pm 0.4$ & $1.6 \pm 0.4$ \\
First AP $(\mathrm{pA})$ & $16.4 \pm 2.4$ & $26.4 \pm 4.3$ & $13.3 \pm 1.7$ & $14.44 \pm 2.4$ & $20.8 \pm 2.3$ & $29.2 \pm 3.6$ \\
Spike threshold $(\mathrm{mV})$ & $-34.2 \pm 0.7$ & $-36.2 \pm 0.8$ & $-34.5 \pm 1.5$ & $-37.40 \pm 1.8$ & $-33.7 \pm 1.2$ & $-34.5 \pm 1.5$ \\
Spike amplitude $(\mathrm{mV})$ & $75.3 \pm 2.1$ & $77.6 \pm 1.9$ & $78.9 \pm 1.6$ & $79.01 \pm 1.8$ & $77.5 \pm 1.3$ & $76.1 \pm 1.9$ \\
Spike half width $(\mathrm{ms})$ & $1.9 \pm 0.1$ & $1.7 \pm 0.1$ & $1.6 \pm 0.2$ & $1.45 \pm 0.1$ & $2.6 \pm 0.3$ & $2.3 \pm 0.2$ \\
\hline
\end{tabular}

Figure 2. BDNF reduces excitability of ovBNST type I-III neurons. $\boldsymbol{a}$, Representative voltage traces of ovBNST type I-III neurons in response to both depolarizing and hyperpolarizing current injection (-60,-50, -40, $+60 \mathrm{pA}$; duration, $1000 \mathrm{~s}$ ) under baseline condition (top) and after $10 \mathrm{~min}$ of BDNF application (1 nм; bottom traces). Prevailing membrane potential was set to $-60 \mathrm{mV}$ under each condition. Arrowheads indicate characteristics important for classification (rebound burst firing, inward rectification). $\boldsymbol{b}$, Spike firing (averaged number of spike) in response to injection of rectangular current pulses ( $1 \mathrm{~s}$ duration; $\mathrm{pA}$ as indicated) at baseline (gray circles) and during BDNF application (10 min, $1 \mathrm{~nm}$; black squares). Note the significant reduction of spike firing in all types of neurons during action of BDNF. c, Intrinsic membrane properties of ovBNST type I-III under baseline conditions and during BDNF application (10 min, 1 nM). Note BDNF-induced membrane hyperpolarization from resting MP in all three types of neurons. For statistics, two-way ANOVA followed by a Bonferroni post hoc analysis, was used. Intrinsic properties were analyzed by using Student's $t$ test. $* p<0.05 ; * * p<0.01 ; * * * p<0.001$

compared with BAPTA-treated cells $(p=0.001)$. Next, to identify the BDNF-induced current, a voltage-clamp ramp protocol $(-80$ to $-120 \mathrm{mV}, 5 \mathrm{~s})$ was applied, and current-voltage $(I-V)$ relationships were constructed under control conditions and during action of BDNF (Fig. $5 a$ ). Current responses were averaged $(n=5 / 4)$ under stable baseline conditions and during near-maximal effect of BDNF, respectively. BDNF induced an outward current that reversed at $-100.41 \pm 9.94 \mathrm{mV}$ (Fig. $5 b$ ), a value close to the estimated $\mathrm{K}^{+}$equilibrium potential for the present recording conditions $(-103.1 \mathrm{mV})$. Furthermore, the $I-V$ relationship revealed inwardly rectifying properties of the BDNF-induced current (Fig. 5b).
$\mathrm{BDNF} /$ TrkB signaling is essential for long-term depression in ovBNST neurons

Next, we examined a possible effect of BDNF on synaptic plasticity. A low-frequency stimulation protocol $(10 \mathrm{~Hz} ; 10 \mathrm{~min})$, as described earlier in BNST neurons (Puente et al., 2011), evoked long-term depression in ovBNST neurons (Fig. 6). Mean amplitudes of eEPSCs after 40-45 min were compared with mean baseline values. Repeated-measures ANOVA revealed a significant time $\times$ group interaction $\left(F_{(7,51)}=3.141, p=0.008\right)$, main effect of time $\left(F_{(1,51)}=13.72, p<0.001\right)$, and main effect of group $\left(F_{(7,51)}=3.545, p=0.004\right)$. Subsequent post hoc analysis 

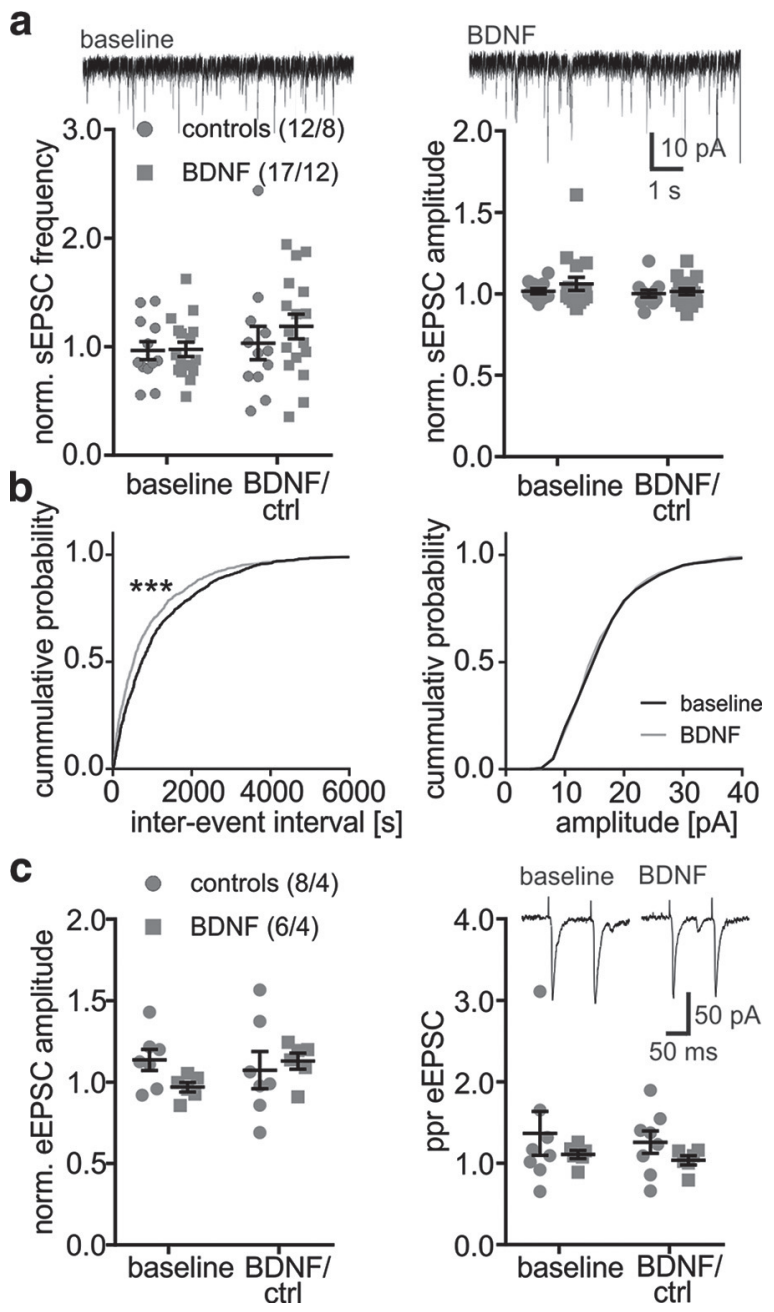

Figure 3. Excitatory postsynaptic activity in ovBNST neurons at baseline and during BDNF application. $\boldsymbol{a}$, Scattered dot plot (mean and SEM shown in black) of average sEPSC frequency (left) and average sEPSC amplitude (right) at baseline (control group, circles; BDNF group, squares) and BDNF/ACSF application; BDNF bath application had no influence on average frequency or amplitude of sEPSC. Example traces showing SEPSCS under baseline and BDNF conditions. $\boldsymbol{b}$, Cumulative probability plots for sEPSC frequencies (left) and amplitudes (right). The sEPSC frequency shows a significant increase after BDNF application. c, Scattered dot plot (mean and SEM shown in black) of eEPSC amplitude (left) and PPR (right) of eEPSCs at baseline (control group, circles; BDNF group, squares) and BDNF/ACSF application. eEPSCs were evoked through electrical microstimulation of the local neuropil. Both amplitudes and PPR of eEPSCs were not affected by BDNF application. Example traces of eEPSCs under baseline and BDNF condition. For statistics, one-way ANOVA followed by a Bonferroni post hoc analysis, whenever appropriate, was used. $* * * p<0.001$.

revealed significantly reduced amplitudes of eEPSCs $40-45 \mathrm{~min}$ poststimulation compared with both baseline $(p=0.004)$ and nonstimulated controls $(p=0.01$; Fig. $6 b, d)$. To assess the possible involvement of BDNF/TrkB signaling, TrkB receptor activation was blocked by applying K252a or ANA-12 (Fig. 6c). Slice incubation with K252a for $>30$ min before LFS prevented LTD (K252a vs baseline, $p>0.99$; K252a vs LTD, $p=0.01$; Fig. $6 c, d$ ). To verify that the observed effect is TrkB dependent, slices were preincubated for $>30 \mathrm{~min}$ with the TrkB-specific antagonist ANA-12 before LFS, again resulting in prevention of LTD (ANA-12 vs baseline, $p>0.99$; ANA-12 vs LTD, $p=0.004$; Fig. $6 c, d)$. Furthermore, the inclusion of BAPTA prevented LTD (BAPTA $10 / 30 \mu \mathrm{M}$ vs baseline, $p>0.99$; BAPTA $30 \mu \mathrm{M}$ vs BDNF, $p=0.006$; Fig. $6 d$ ). Finally, we treated the slices with TrkB FC chimera protein, a high-affinity BDNF scavenger.
Exogenously applied TrkB FC is suited to inhibit acute BDNF effects at synaptic sides. Scavenging BDNF resulted in a prevention of LTD (TrkB FC vs baseline, $p>0.99$; TrkB FC vs BDNF, $p=0.004$; Fig. $6 c, d)$.

\section{Discussion}

In this study, we found both BDNF and its high-affinity receptor TrkB to be highly abundant in the ovBNST and demonstrated $\mathrm{BDNF} /$ TrkB signaling to dampen the activity of ovBNST neurons by short-term and long-term postsynaptic mechanisms. $\mathrm{BDNF} /$ TrkB signaling induced an increase in membrane $\mathrm{K}^{+}$ conductance, resulting in reduced excitability, and contributes to LTD induction in ovBNST neurons.

BDNF immunoreactivity in the ovBNST was most obvious in the neuropil and in perinuclear structures of cell somata (Fig. 1, white arrows). This finding is in line with earlier immunohistological investigations, describing BDNF protein labeling within the BNST of rats (Conner et al., 1997), prairie voles (Liu et al., 2001), and mice (Greenberg et al., 2014). Studies using in situ hybridization showed no BDNF-encoding RNA within BNST neurons, suggesting anterograde transport of BDNF to the BNST from other brain regions (Conner et al., 1997; Liu et al., 2001). However, there are also studies showing BDNF mRNA expression in the BNST of mice (Greenberg et al., 2014) and rats (Hammack et al., 2009). In the context of these contradictions, our data reveal that both $\mathrm{BDNF}$ and its receptor TrkB are abundantly available in the ovBNST.

The existence of at least three different subclasses of neurons (type I-III), distinguishable based on their expression of intrinsic membrane currents, has been described for the BNST recently (Hammack et al., 2007; Rodríguez-Sierra et al., 2013; Daniel et al., 2017). Further, in addition to differences in their physiology, ovBNST neurons can be genetically subdivided. For instance, the majority of type III neurons were found to express mRNA transcripts for CRF and to exhibit unique ion channel expression patterns (Hazra et al., 2011; Dabrowska et al., 2013), and both electrophysiological properties and CRF mRNA expression were altered exclusively in type III neurons in an animal model of chronic stress (Daniel et al., 2019). Here, we show a BDNF-mediated membrane hyperpolarization and decrease in spike activity in ovBNST neurons, with no apparent differences among the three different subclasses. Despite physiological and genetic differences, BDNF/TrkB signaling thus seems to be inherent to all major types of neurons in ovBNST, suggesting a rather general regulatory function of the $\mathrm{BDNF} / \mathrm{TrkB}$ system.

Bath application of BDNF induced a hyperpolarizing shift of the resting membrane potential, mediated by an outward membrane current. This response involves $\mathrm{BDNF} / \mathrm{TrkB}$ signaling, as blocking TrkB receptor activity by either K252a, a kinase inhibitor, or ANA-12, a specific antagonist for TrkB, abolished the BDNF-induced outward current. Further, a significant hyperpolarizing shift of the membrane potential in response to BDNF existed in the presence of TTX, indicating independence on synaptic network activities. We further confirmed this effect to be mediated by postsynaptic mechanisms, as BAPTA added to the internal solution prevented the hyperpolarizing response of ovBNST neurons. To identify the ion carrying the BDNFinduced current, we constructed $I-V$ relationships from ramp recordings under voltage-clamp conditions obtained at baseline and during near-maximal responses to BDNF. $I-V$ revealed a reversal potential of the BDNF-induced current matching the estimated equilibrium potential of $\mathrm{K}^{+}$ions in our experiments, 

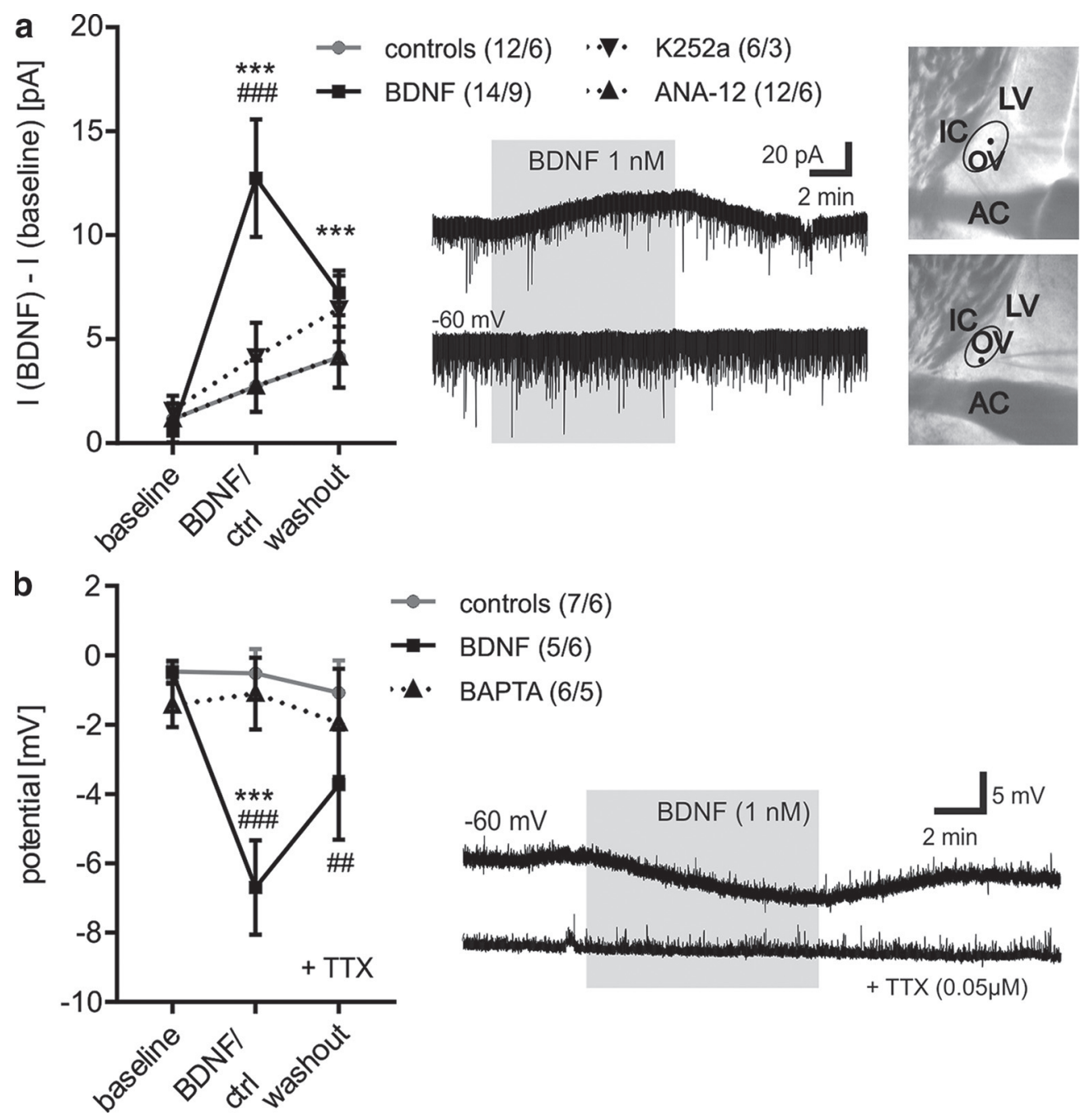

Figure 4. BDNF affects holding current and membrane potential of ovBNST neurons. $\boldsymbol{a}$, BDNF bath application (10 min, $1 \mathrm{~nm})$ caused a significant outwardly directed current compared with controls. This effect of BDNF was blocked by K252a (200 nM) and ANA-12 (10 $\mu \mathrm{m})$, respectively. Representative example traces of voltage-clamp measurements at $-60 \mathrm{mV}$ showing an outward current following BDNF application. Example pictures (top right) showing the location of the patch pipette in ovBNST. $\boldsymbol{b}$, Significant hyperpolarization of ovBNST neurons during BDNF bath application (1 nM, $10 \mathrm{~min})$ compared with controls. Intracellular BAPTA $(10 \mu \mathrm{m})$ blocked the effect of BDNF. Note that TTX $(0.5 \mu \mathrm{m})$ was applied additionally to minimize presynaptic influence. Representative example traces of current-clamp measurements at $-60 \mathrm{mV}$ showing hyperpolarization shift because of BDNF application. For statistics, repeated-measures ANOVA followed by a Bonferroni post hoc analysis, whenever appropriate, was used. $* * * p<0.001$ compared with controls. \#\#p $<0.01$; \#\#p $<0.001$ compared with baseline.

indicating that $\mathrm{K}^{+}$is predominantly involved in the BDNF-induced increase in membrane conductance. BDNF/TrkB signaling was previously observed to act on a variety of $\mathrm{K}^{+}$currents in neurons, including $\mathrm{M}$-type $\mathrm{K}^{+}$currents, A-type $\mathrm{K}^{+}$currents, but also activation of G-protein-dependent cascades (Adamson et al., 2002; Tucker and Fadool, 2002; Nieto-Gonzalez and Jensen, 2013). For instance, BDNF/TrkB signaling was found to modulate voltage-gated $\mathrm{K}^{+}$channels and thus affect neuronal excitability of dentate gyrus interneurons (Nieto-Gonzalez and Jensen, 2013). Application of $a K_{v} 7 / K C N Q$ channel antagonist inhibited the BDNF effect, whereas $\mathrm{K}_{\mathrm{v}}$ 7/ KCNQ channel opener could mimic the effect of BDNF, supporting a potential role for M-currents in the modulation of neuronal excitability (Nieto-Gonzalez and Jensen, 2013). Although we cannot make any conclusive statement on the type of $\mathrm{K}^{+}$channel activated in ovBNST
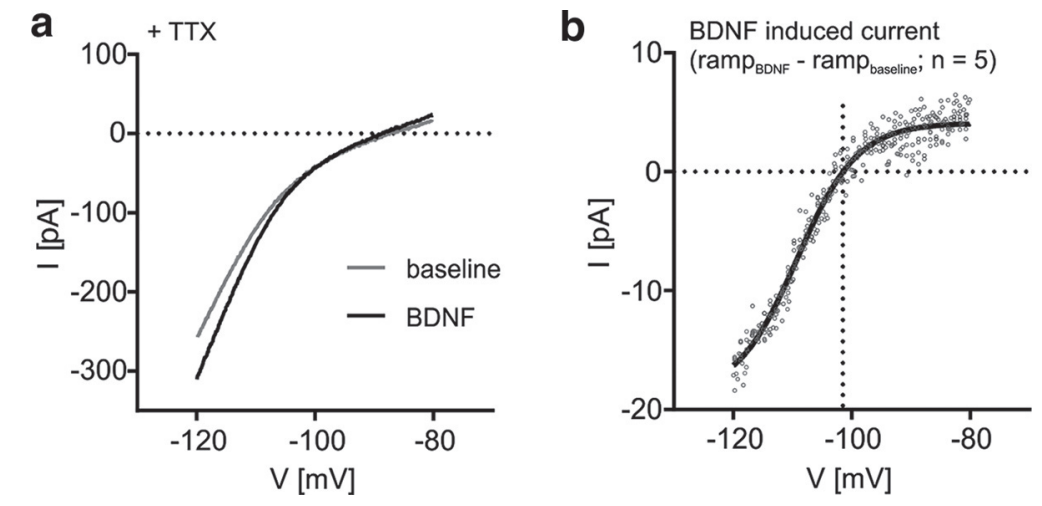

Figure 5. Current versus voltage (I/V) relationship in ovBNST neurons in response to BDNF application. Membrane potential was moved under voltage-clamp condition in a ramp-like fashion from -80 to $-120 \mathrm{mV}$ over $5 \mathrm{~s}$ with an intertrial interval of $45 \mathrm{~s}$. $\boldsymbol{a}$, Representative example traces of a whole-cell current response of an ovBNST neuron to the voltage ramp under baseline (gray) and BDNF (black) conditions (averaged traces, three traces for each condition). $\boldsymbol{b}$, BDNF-induced current calculated from the subtraction of currents obtained under BDNF and control conditions (fitted curve, dots indicate single data points; $n=5 / 4$ ). 
a

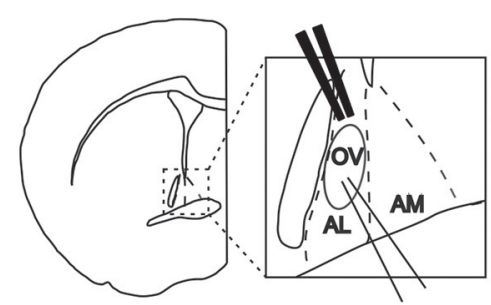

C

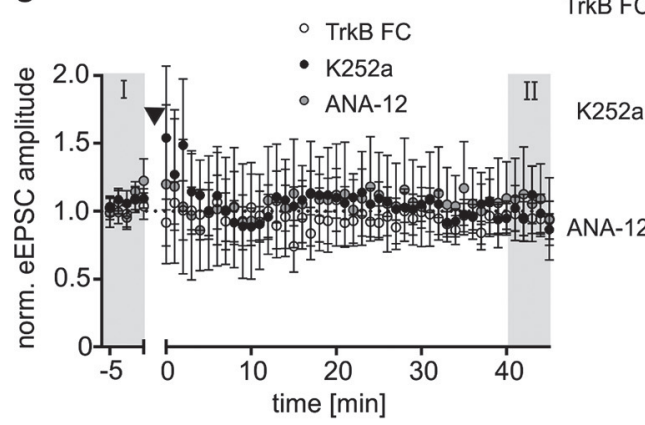

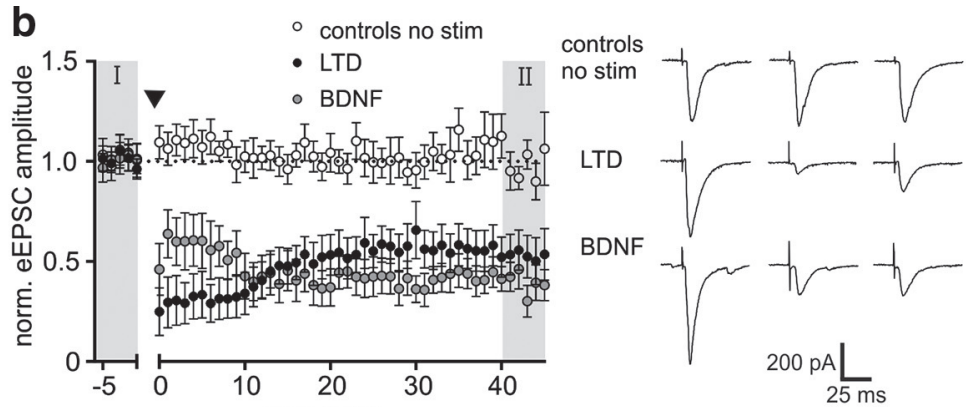

d

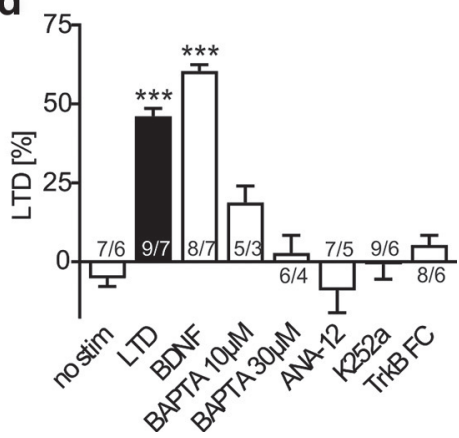

Figure 6. LTD in ovBNST neurons is BDNF dependent. $\boldsymbol{a}$, Schematic view of stimulation and recording site in ovBNST. AL, Laterodorsal BNST; AM, lateromedial BNST. $\boldsymbol{b}$, Low-frequency stimulation (10 min, $10 \mathrm{~Hz}$ ) induces LTD in ovBNST neurons (black dots). BDNF application (1 nм, $10 \mathrm{~min}$ ) altered the early time course of this LTD (gray dots). c, Low-frequency stimulation (10 min, $10 \mathrm{~Hz}$ ) fails to evoke LTD during preincubation of slices with TrkB FC (white dots), K252a (black dots), or ANA-12 (gray dots). Example traces showing response to stimulation before, shortly after, and $45 \mathrm{~min}$ after low-frequency stimulation under various conditions. $\boldsymbol{d}$, Average of eEPSC amplitudes after 40-45 min following LTD induction (gray box; I) compared with the average of baseline eEPSC amplitudes (gray box; II) under various conditions. LTD was absent when slices were incubated with K252a (200 nM), ANA-12 (10 $\mu \mathrm{m})$, or TrkB FC (100 ng/ml), respectively. Intracellular BAPTA $(10 \mu \mathrm{m} ; 30 \mu \mathrm{m})$ blocks LTD. For statistics, multiple comparisons ANOVA followed by a Bonferroni post hoc analysis, whenever appropriate, was used. $\nabla$, Time point of LFS; $* * * p<0.001$ compared with baseline.

neurons, sensitivity of the BDNF-induced current to BAPTA indicates involvement of intracellular $\mathrm{Ca}^{2+}$. Previous reports on parallel changes of BDNF mRNA expression and small-conductance $\mathrm{Ca}^{2+}$-activated $\mathrm{K}^{+}$current (Kramár et al., 2004; Jacobsen et al., 2009) suggest the involvement of a $\mathrm{Ca}^{2+}$-dependent $\mathrm{K}^{+}$ channels in BDNF responses in ovBNST neurons. Of course, other sites of intracellular $\mathrm{Ca}^{2+}$ influence cannot be excluded. Of note, the $I-V$ relationship of the BDNF-induced $\mathrm{K}^{+}$current displays inward rectification, highlighting the contribution of an inwardly rectifying $\mathrm{K}^{+}\left(\mathrm{K}_{\mathrm{ir}}\right)$ channel. The majority of $\mathrm{K}_{\mathrm{ir}}$ channels is modulated by phosphatidylinositol 4,5-bisphosphate, which in turn is activated by PLC $\gamma$ (Hibino et al., 2010; Leal et al., 2017). The PLC $\gamma$ pathway is one of the three main intracellular signaling cascades downstream of TrkB receptors. Therefore, activation of the PLC $\gamma$ pathway and thus activation of $\mathrm{K}_{\mathrm{ir}}$ channels by BDNF is also conceivable.

Overall, BDNF significantly reduced the excitability in all major subclasses of ovBNST neurons, indicating dampening of neuronal activity in ovBNST by short-term mechanisms. Indeed, TrkB receptor activation has been shown previously to affect neuronal properties, including excitability, synaptic transmission, and plasticity (Lohof et al., 1993; Kossel et al., 2001; Kovalchuk et al., 2002; Blum and Konnerth, 2005; Li et al., 2012; Park and Poo, 2013; Panja et al., 2014; Vignoli et al., 2016). With respect to synaptic activity in ovBNST, BDNF application did not affect amplitudes or frequencies of sEPSCs and eEPSCs, although we observed a slightly different distribution of sEPSC frequencies during action of BDNF. Furthermore, BDNF did not affect PPR of eEPSCs. Yet, the effects of BDNF on synaptic transmission of neurons in other brain regions have been described earlier (Zhu and Roper, 2001). Thus, differences in responsiveness to BDNF application might be because of cellular or regional differences, highlighting the specificity of neuronal effects driven by BDNF/TrkB signaling.

In the next set of experiments, we were interested in dampening of neuronal excitability by $\mathrm{BDNF} / \mathrm{TrkB}$ signaling in the ovBNST at long-term scales. Therefore, we investigated the influence of BNDF on long-term synaptic plasticity, using an experimental induction protocol previously established in BNST neurons (Puente et al., 2011). We found induction of LTD to be dependent on BDNF/TrkB signaling as (1) blocking TrkB receptor activity by either K252a or ANA-12, and (2) scavenging of extracellular BDNF prevented LTD. Furthermore, sensitivity to BAPTA of both LTD and BDNF-induced increase in $\mathrm{K}^{+}$conductance suggests a convergence of postsynaptic intracellular signaling pathways via intracellular $\mathrm{Ca}^{2+}$. In keeping with this, LTD induction in BNST neurons has been described to depend on postsynaptic mechanisms (Puente et al., 2011). The present finding that this LTD was induced under voltage-clamp conditions, largely preventing changes in postsynaptic membrane potential, would argue against such a postsynaptic mechanism (Wozny et al., 2008), although postsynaptic induction sites might have escaped proper voltage-clamp because of limited space-clamp properties. Previous studies on BDNF-induced changes in synaptic activity reported on both presynaptic and postsynaptic sites of action (Gottschalk et al., 1998; Xu et al., 2000; Kovalchuk et al., 2002; Meis et al., 2012; Edelmann et al., 2015). For instance, BDNF/TrkB signaling in LA is required for LTP induction at thalamo-amygdala afferents and relies on postsynaptic mechanisms (Meis et al., 2012). Heterozygous genetic BDNF deletion in mice indeed resulted in deficits of postsynaptic LTP, paralleled by deficits in acquisition and consolidation of fear memory (Meis et al., 2012, 2018).

The BNST, embedded in an extended amygdala circuit, is regarded as an important structure mediating stress and anxiety 
states as well as controlling defensive behaviors (Davis et al., 2010; Avery et al., 2016; Lange et al., 2016; Ch'ng et al., 2018). Exposure to various stressors is thought to link to alterations in synaptic plasticity within the BNST (Harris and Winder, 2018). For instance, acute stress reverted LTD into LTP in neurons of the anterior BNST, thus directly affecting long-term plasticity processes (Glangetas et al., 2013). Optogenetic inhibition of the ovBNST in mice dampened anxiety-like behavior, indicating a stress-provoking or anxiety-provoking role of ovBNST neurons (Kim et al., 2013). Moreover, most neurons in ovBNST express CRF (Dabrowska et al., 2013). Chronic stress indeed altered electrophysiological properties and CRF mRNA expression in a specific subclass of BNST neurons (Daniel et al., 2019), and chronic variable mild stress induced maladaptive behaviors through the activation of CRF signaling associated with a decrease in membrane $\mathrm{K}^{+}$current in ovBNST neurons in mice (Hu et al., 2020). With respect to $\mathrm{BDNF}$, one line of evidence indicates that chronic stress increases transcript expression for BDNF in rats (Hammack et al., 2009), whereas defeat stress increased BDNF protein but not mRNA in BNST in the same species (Greenberg et al., 2014). Along another line, several studies in rodents and humans demonstrated that both chronic and acute stress reduce BDNF levels in various brain regions (Murakami et al., 2005; Grønli et al., 2006; Mondelli, 2014). While BDNF expression after stress exposure remains to be studied in ovBNST, we hypothesize that stress results in a reduction in BDNF expression in this region, thereby counteracting BDNF-induced depression of synaptic and spike activity. Such a scenario would comply with previous findings that stress increases the excitability of ovBNST neurons, accompanied by reduced membrane $\mathrm{K}^{+}$conductance (Hu et al., 2020), and that stress leads to reversal of LTD into LTP in anterior BNST neurons (Glangetas et al., 2013).

Overall, BDNF/TrkB signaling dampens activity in ovBNST neurons at short-term and long-term timescales, thereby counteracting increases in excitability as for instance occurring during stress exposure or fear responses. Thus, BDNF/TrkB signaling in ovBNST seems to constitute a synaptic entry point to stress adaptation via a decrease in the excitability of ovBNST neurons, and disturbance of the BDNF system in ovBNST depicts a risk for the development of stress-related maladaptive behaviors.

\section{References}

Adamson CL, Reid MA, Davis RL (2002) Opposite actions of brain-derived neurotrophic factor and neurotrophin-3 on firing features and ion channel composition of murine spiral ganglion neurons. J Neurosci 22:13851396.

Avery SN, Clauss JA, Blackford JU (2016) The human BNST: functional role in anxiety and addiction. Neuropsychopharmacology 41:126-141.

Blum R, Konnerth A (2005) Neurotrophin-mediated rapid signaling in the central nervous system: mechanisms and functions. Physiology (Bethesda) 20:70-78.

Ch'ng S, Fu J, Brown RM, McDougall SJ, Lawrence AJ (2018) The intersection of stress and reward: BNST modulation of aversive and appetitive states. Prog Neuropsychopharmacol Biol Psychiatry 87:108-125.

Conner JM, Lauterborn JC, Yan Q, Gall CM, Varon S (1997) Distribution of brain-derived neurotrophic factor (BDNF) protein and mRNA in the normal adult rat CNS: evidence for anterograde axonal transport. J Neurosci 17:2295-2313.

Dabrowska J, Hazra R, Guo J-D, DeWitt S, Rainnie DG (2013) Central CRF neurons are not created equal: phenotypic differences in CRF-containing neurons of the rat paraventricular hypothalamus and the bed nucleus of the stria terminalis. Front Neurosci 7:156.

Daftary SS, Calderon G, Rios M (2012) Essential role of brain-derived neurotrophic factor in the regulation of serotonin transmission in the basolateral amygdala. Neuroscience 224:125-134.
Daniel SE, Guo J, Rainnie DG (2017) A comparative analysis of the physiological properties of neurons in the anterolateral bed nucleus of the stria terminalis in the Mus musculus, Rattus norvegicus, and Macaca mulatta. J Comp Neurol 525:2235-2248.

Daniel SE, Menigoz A, Guo J, Ryan SJ, Seth S, Rainnie DG (2019) Chronic stress induces cell type-selective transcriptomic and electrophysiological changes in the bed nucleus of the stria terminalis. Neuropharmacology 150:80-90.

Davis M, Walker DL, Miles L, Grillon C (2010) Phasic vs sustained fear in rats and humans: role of the extended amygdala in fear vs anxiety. Neuropsychopharmacology 35:105-135.

Edelmann E, Cepeda-Prado E, Franck M, Lichtenecker P, Brigadski T, Leßmann V (2015) Theta burst firing recruits BDNF release and signaling in postsynaptic CA1 neurons in spike-timing-dependent LTP. Neuron 86:1041-1054.

Figurov A, Pozzo-Miller LD, Olafsson P, Wang T, Lu B (1996) Regulation of synaptic responses to high-frequency stimulation and LTP by neurotrophins in the hippocampus. Nature 381:706-709.

Glangetas C, Girard D, Groc L, Marsicano G, Chaouloff F, Georges F (2013) Stress switches cannabinoid type-1 (CB1) receptor-dependent plasticity from LTD to LTP in the bed nucleus of the stria terminalis. J Neurosci 33:19657-19663.

Gottschalk W, Pozzo-Miller LD, Figurov A, Lu B (1998) Presynaptic modulation of synaptic transmission and plasticity by brain-derived neurotrophic factor in the developing hippocampus. J Neurosci 18:6830-6839.

Greenberg GD, Laman-Maharg A, Campi KL, Voigt H, Orr VN, Schaal L, Trainor BC (2014) Sex differences in stress-induced social withdrawal: role of brain derived neurotrophic factor in the bed nucleus of the stria terminalis. Front Behav Neurosci 7:223.

Grønli J, Bramham C, Murison R, Kanhema T, Fiske E, Bjorvatn B, Ursin R, Portas CM (2006) Chronic mild stress inhibits BDNF protein expression and CREB activation in the dentate gyrus but not in the hippocampus proper. Pharmacol Biochem Behav 85:842-849.

Hammack SE, Mania I, Rainnie DG (2007) Differential expression of intrinsic membrane currents in defined cell types of the anterolateral bed nucleus of the stria terminalis. J Neurophysiol 98:638-656.

Hammack SE, Cheung J, Rhodes KM, Schutz KC, Falls WA, Braas KM, May V (2009) Chronic stress increases pituitary adenylate cyclase-activating peptide (PACAP) and brain-derived neurotrophic factor (BDNF) mRNA expression in the bed nucleus of the stria terminalis (BNST): roles for PACAP in anxiety-like behavior. Psychoneuroendocrinology 34:833-843.

Harris NA, Winder DG (2018) Synaptic plasticity in the bed nucleus of the stria terminalis: underlying mechanisms and potential ramifications for reinstatement of drug- and alcohol-seeking behaviors. ACS Chem Neurosci 9:2173-2187.

Hazra R, Guo J-D, Ryan SJ, Jasnow AM, Dabrowska J, Rainnie DG (2011) A transcriptomic analysis of type I-III neurons in the bed nucleus of the stria terminalis. Mol Cell Neurosci 46:699-709.

Hibino H, Inanobe A, Furutani K, Murakami S, Findlay I, Kurachi Y (2010) Inwardly rectifying potassium channels: their structure, function, and physiological roles. Physiol Rev 90:291-366.

Hu P, Liu J, Maita I, Kwok C, Gu E, Gergues MM, Kelada F, Phan M, Zhou J-N, Swaab DF, Pang ZP, Lucassen PJ, Roepke TA, Samuels BA (2020) Chronic stress induces maladaptive behaviors by activating corticotropin-releasing hormone signaling in the mouse oval bed nucleus of the stria terminalis. J Neurosci 40:2519-2537.

Jacobsen JPR, Redrobe JP, Hansen HH, Petersen S, Bond CT, Adelman JP, Mikkelsen JD, Mirza NR (2009) Selective cognitive deficits and reduced hippocampal brain-derived neurotrophic factor mRNA expression in smallconductance calcium-activated $\mathrm{K}+$ channel deficient mice. Neuroscience 163:73-81.

Kim S-Y, Adhikari A, Lee SY, Marshel JH, Kim CK, Mallory CS, Lo M, Pak S, Mattis J, Lim BK, Malenka RC, Warden MR, Neve R, Tye KM, Deisseroth K (2013) Diverging neural pathways assemble a behavioural state from separable features in anxiety. Nature 496:219-223.

Korte M, Carroll P, Wolf E, Brem G, Thoenen H, Bonhoeffer T (1995) Hippocampal long-term potentiation is impaired in mice lacking brainderived neurotrophic factor. Proc Natl Acad Sci U S A 92:8856-8860.

Kossel AH, Cambridge SB, Wagner U, Bonhoeffer T (2001) A caged Ab reveals an immediate/instructive effect of BDNF during hippocampal synaptic potentiation. Proc Natl Acad Sci U S A 98:14702-14707. 
Kovalchuk Y, Hanse E, Kafitz KW, Konnerth A (2002) Postsynaptic induction of BDNF-mediated long-term potentiation. Science 295:1729-1734.

Kramár EA, Lin B, Lin CY, Arai AC, Gall CM, Lynch G (2004) A novel mechanism for the facilitation of theta-induced long-term potentiation by brain-derived neurotrophic factor. J Neurosci 24:5151-5161.

Lange MD, Jüngling K, Paulukat L, Vieler M, Gaburro S, Sosulina L, Blaesse P, Sreepathi HK, Ferraguti F, Pape HC (2014) Glutamic acid decarboxylase 65: a link between GABAergic synaptic plasticity in the lateral amygdala and conditioned fear generalization. Neuropsychopharmacology 39:2211-2220.

Lange MD, Daldrup T, Remmers F, Szkudlarek HJ, Lesting J, Guggenhuber S, Ruehle S, Jüngling K, Seidenbecher T, Lutz B, Pape HC (2016) Cannabinoid CB1 receptors in distinct circuits of the extended amygdala determine fear responsiveness to unpredictable threat. Mol Psychiatry 22:1422-1429.

Leal G, Bramham CR, Duarte CB (2017) BDNF and hippocampal synaptic plasticity. Vitam Horm 104:153-195.

Lebow M, Chen A (2016) Overshadowed by the amygdala: the bed nucleus of the stria terminalis emerges as key to psychiatric disorders. Mol Psychiatry 21:450-463.

Li C, Dabrowska J, Hazra R, Rainnie DG (2011) Synergistic activation of dopamine $\mathrm{D} 1$ and $\mathrm{TrkB}$ receptors mediate gain control of synaptic plasticity in the basolateral amygdala. PLoS One 6:e26065.

Li W, Calfa G, Larimore J, Pozzo-Miller L (2012) Activity-dependent BDNF release and TRPC signaling is impaired in hippocampal neurons of Mecp2 mutant mice. Proc Natl Acad Sci U S A 109:17087-17092.

Liu Y, Fowler CD, Young LJ, Yan Q, Insel TR, Wang Z (2001) Expression and estrogen regulation of brain-derived neurotrophic factor gene and protein in the forebrain of female prairie voles. J Comp Neurol 433:499514.

Lohof AM, Ip NY, Poo MM (1993) Potentiation of developing neuromuscular synapses by the neurotrophins NT-3 and BDNF. Nature 363:350-353.

Martinowich K, Manji H, Lu B (2007) New insights into BDNF function in depression and anxiety. Nat Neurosci 10:1089-1093.

Meis S, Endres T, Lessmann V (2012) Postsynaptic BDNF signalling regulates long-term potentiation at thalamo-amygdala afferents. J Physiol 590:193208.

Meis S, Endres T, Munsch T, Lessmann V (2018) The relation between longterm synaptic plasticity at glutamatergic synapses in the amygdala and fear learning in adult heterozygous BDNF-knockout mice. Cereb Cortex 28:1195-1208.

Miles OW, Maren S (2019) Role of the bed nucleus of the stria terminalis in PTSD: insights from preclinical models. Front Behav Neurosci 13:68

Mondelli V (2014) From stress to psychosis: whom, how, when and why? Epidemiol Psychiatr Sci 23:215-218.

Murakami S, Imbe H, Morikawa Y, Kubo C, Senba E (2005) Chronic stress, as well as acute stress, reduces BDNF mRNA expression in the rat hippocampus but less robustly. Neurosci Res 53:129-139.

Musumeci G, Sciarretta C, Rodríguez-Moreno A, Al Banchaabouchi M, Negrete-Díaz V, Costanzi M, Berno V, Egorov AV, Von Bohlen Und Halbach O, Cestari V, Delgado-García JM, Minichiello L (2009) TrkB modulates fear learning and amygdalar synaptic plasticity by specific docking sites. J Neurosci 29:10131-10143.
Nieto-Gonzalez JL, Jensen K (2013) BDNF depresses excitability of parvalbumin-positive interneurons through an M-like current in rat dentate gyrus. PLoS One 8:e67318.

Ou L-C, Gean P-W (2006) Regulation of amygdala-dependent learning by brain-derived neurotrophic factor is mediated by extracellular signal-regulated kinase and phosphatidylinositol-3-kinase. Neuropsychopharmacology 31:287-296.

Panja D, Kenney JW, D’Andrea L, Zalfa F, Vedeler A, Wibrand K, Fukunaga R, Bagni C, Proud CG, Bramham CR (2014) Two-stage translational control of dentate gyrus LTP consolidation is mediated by sustained BDNFTrkB signaling to MNK. Cell Rep 9:1430-1445.

Pape H-C, Pare D (2010) Plastic synaptic networks of the amygdala for the acquisition, expression, and extinction of conditioned fear. Physiol Rev 90:419-463.

Park H, Poo MM (2013) Neurotrophin regulation of neural circuit development and function. Nat Rev Neurosci 14:7-23.

Puente N, Cui Y, Lassalle O, Lafourcade M, Georges F, Venance L, Grandes P, Manzoni OJ (2011) Polymodal activation of the endocannabinoid system in the extended amygdala. Nat Neurosci 14:1542-1547.

Rattiner LM, Davis M, Ressler KJ (2005) Brain-derived neurotrophic factor in amygdala-dependent learning. Neuroscientist 11:323-333.

Rodríguez-Sierra OE, Turesson HK, Pare D, Rodríguez-Sierra OE, Turesson HK, Pare D (2013) Contrasting distribution of physiological cell types in different regions of the bed nucleus of the stria terminalis. J Neurophysiol 110:2037-2049

Thoenen H (1995) Neurotrophins and neuronal plasticity. Science 270:593598.

Tovote P, Esposito MS, Botta P, Chaudun F, Fadok JP, Markovic M, Wolff SBE, Ramakrishnan C, Fenno L, Deisseroth K, Herry C, Arber S, Lüthi A (2016) Midbrain circuits for defensive behaviour. Nature 534:206-212.

Tucker K, Fadool DA (2002) Neurotrophin modulation of voltage-gated potassium channels in rat through TrkB receptors is time and sensory experience dependent. J Physiol 542:413-429.

Vignoli B, Battistini G, Melani R, Blum R, Santi S, Berardi N, Canossa M (2016) Peri-synaptic glia recycles brain-derived neurotrophic factor for LTP stabilization and memory retention. Neuron 92:873-887.

Vranjkovic O, Pina M, Kash TL, Winder DG (2017) The bed nucleus of the stria terminalis in drug-associated behavior and affect: a circuit-based perspective. Neuropharmacology 122:100-106.

Walter AL, Bartsch JC, Datunashvili M, Blaesse P, Lange MD, Pape H (2018) Physiological profile of neuropeptide Y-expressing neurons in bed nucleus of stria terminalis in mice: state of high excitability. Front Cell Neurosci 12:393.

Wozny C, Maier N, Schmitz D, Behr J (2008) Two different forms of longterm potentiation at CA1-subiculum synapses. J Physiol 586:2725-2734.

Xu B, Gottschalk W, Chow A, Wilson RI, Schnell E, Zang K, Wang D, Nicoll RA, Lu B, Reichardt LF (2000) The role of brain-derived neurotrophic factor receptors in the mature hippocampus: modulation of long-term potentiation through a presynaptic mechanism involving trkB. J Neurosci 20:6888-6897.

Zhu WJ, Roper SN (2001) Brain-derived neurotrophic factor enhances fast excitatory synaptic transmission in human epileptic dentate gyrus. Ann Neurol 50:188-194. 